\title{
Reviews of books and studies
}

\author{
A.F. Tempelaar, Veiligheid en risico in de gezondheidszorg ('Safety and risk in health \\ care'). Scriptie Nederlands Instituut voor Praeventieve Gezondheidszorg TNO, 1990.
}

'Veiligheid en risico in de gezondheidszorg' is the result of a literature study on safety in health care in general, and drug safety in particular. The author, as a general practitioner, is intrigued by the problem of iatrogenic complications. Based on national and international publications he gives estimates of the volume of iatrogenic damage in The Netherlands. Of all hospital admissions $4-5 \%$ are expected to be caused by iatrogenic complications; $15-30 \%$ of all patients in hospitals are expected to endure iatrogenic damage (such as nosocomial infections, accidents, complications of the therapy); and $0.3-0.5 \%$ of all patients in hospitals are believed to die because of this. It is argued that too much diagnostic testing, as well as too much therapy can be damaging. Examples are presented of the overutilization of laboratory tests, X-rays, antibiotics and antihypertensive treatment. Defensive medicine, misplaced optimism, and an urge for perfection cause overutilization. Other factors that are identified as safety hazards in health care are stress, sleep deprivation, and incompetence. The author propagates better risk management. First of all, this includes more health safety research. To quote the 1990 Elsinore declaration on safety in health care: 'Risks in preventive and therapeutic health care can only be countered if they are known and understood; ... effort is needed to document the nature, severity and frequency of risks and the factors which promote or trigger them'. This research should result in the development of a policy that eliminates all unnecessary risks. Suggestions in this direction include the use of checklists in health care practice, but also changes in the education of doctors with regard to their professional attitude.

In the second part of this report, safety problems with drugs are discussed more extensively. Estimates are presented of the epidemiology of drug unsafety: $3-4 \%$ of all hospital admissions are caused by adverse effects of drugs; $10-18 \%$ of all patients in hospitals experience adverse effects; $0.7 \%$ experience serious damage caused by drugs. Elderly people are identified as a risk group, because of multiple medication, communication problems, and changes in their physiology. The intrinsic safety (or risk) of drugs is reviewed. The limitations of the pre-marketing phase for detection of adverse effects are discussed. Several post marketing surveillance methods are described, such as case reports, voluntary reporting, cohort studies, case-control studies, and record linkage of drug use and morbidity data. None of these methods is ideal for the rapid and sensitive detection and quantification of adverse effects. Therefore, it is argued, a combination of methods is necessary to reduce the intrinsic risk of drugs. After a description of post marketing surveillance in The Netherlands, the author concludes that physicians should learn to focus on drug safety. Audit and cooperation between pharmacists and physicians should lead to a safer use of drugs.

Although 'Veiligheid en risico in de gezondheidszorg' focuses on health care risks in The Netherlands, it discusses many international publications and could be worth reading for anyone interested in estimates of iatrogenic damage and overutilization of health care. The 
report includes an extensive list of references (271) of which almost half are in English. Unfortunately, the report itself is written in Dutch and does not have an English summary. The report or a reprint of the reference list can be ordered from the author: A.F. Tempelaar, O.W.M. Ziekenfonds Oost-Nederland, Postbus 19, 7470 AA Goor, The Netherlands.

Petra Denig Groningen

J.P. Griffin, P.F. d'Arcy and C.J. Speirs. A Manual of Adverse Drug Interactions. 4th edition, Wright, London, 1988, 521 pp., price not quoted.

Despite the publication of a number of similar textbooks on the same subject and despite dire warnings by the editor of The Lancet that compilations of this type could lead to therapeutic paralysis, new editions, of ever increasing bulk, have continued to appear, and the book has even been translated into the German and Japanese languages.

Part 1, a sixty-page introduction, was upgraded to the state-of-the-art in 1985, and it follows the general lines of the series of articles published in the past under the aegis of the editors in the journal Pharmacology and Therapeutics.

Part 2 was edited in the same way as previous editions: a brief introduction for each therapeutic group, followed by tables of drugs with a description of possible interactions and suggestions for their management. The layout has been greatly improved, though that meant increasing the size of the type page to a B5 format, which is unfortunately unwieldy for photocopying. References, lacking titles, can only been found at the end of the chapters, and they are just quoted as is without the critical approach which characterizes standard books like Hansten's or the APhA guide.

A lot of space is used up by mentioning trade names both in the text and the Index, understandable in view of the commercial employment of the first editor, but superfluous in an academic text. Clinically relevant interactions appear in large print, the rare curiosities in a much smaller print.

The usefulness of such a book largely depends on the quality of the database behind it and on regular updating. Both unfortunately are far from optimal, and a number of random comparisons with the American texts produced an unexpectedly great number of gaps.

For practical everyday use I would much prefer Hansten and Horn's ring binder "Drug interactions", which is now in its 6th edition and last updated in October 1990. Though far from cheap it provides extensive coverage of the problem, gives full data and full references, and is much easier to handle. One should - like The Lancet mentioned in 1975 - realize that really dangerous drug interactions are fortunately rare and not always predictable. The present book will probably mainly be used by pharmacists, and by data sheet text writers in industry, and its principal purpose will therefore be to confirm or deny suspicions once the interaction has occurred. 